\title{
Study on the Development Strategy of the Future Library under Information Environment
}

\author{
Junying Yang \\ Public Security Marine Police Academy, Ningbo, China
}

\begin{abstract}
The Internet and the digital revolution has a great influence on every part of society, including the library. The Library must persist in the idea of take the user as the center, constructing resource configuration mode for information environment, form a flexible form of organization and management, and become intelligence center which provides knowledge and public service.
\end{abstract}

KEYWORD: Service of Knowledge; Information Literacy; Organization and Management.

\section{INTRODUCTION}

Global integration and knowledge society has become the development trend in twenty-first Century. The information economy driven by the new technology has brought a great opportunity and challenge to all governments or organizations. As a kind of social knowledge service organizations, library has to change to adapt to the needs of the changing environment.

The Internet and the digital revolution has a great influence on every part of society, including the library, but the essence and core function of library does not change, which is the service and support in the field of cultural and knowledge. Whether now or in the future, the carrier of knowledge may change, but the of people's knowledge needs will only increase with time pass by. Therefore, to support scientific research, support economic development, encourage lifelong learning, promote cultural exchanges, the library will play a decisive role and will be an integral part of society.

The $79^{\text {th }}$ IFLA Governing Board issued "Statement on Libraries and Development" and "Trend Report". In the two documents, IFLA pointed out: By providing various information, services and solutions, the library plays an irreplaceable role in the sustainable development of human society in many fields, including economy, culture and scientific research.[1][2]

In this paper, we will discuss several questions about the development strategy of the future library under information environment.

\section{INNOVATION OF USER SERVICE MODEL}

How to service the customer is most important to the library. Access to information is a fundamental human right that can break the cycle of poverty and support sustainable development. [1] The library provides knowledge service the public, so it must consider the needs of different users and provide multiple services.

\subsection{Providing Service of Knowledge}

The library has done a lot to adapt to changes in user demand of digital network era, including the digital resources expansion, providing information query and access functions. Through these efforts, accessing to the library is very convenient, but this is only the extension of the traditional access function provided by the library. The library still passively accepts user queries, and does not take the initiative to provide better services to the users.

In 2010, the quantity of information transmitted globally exceeded 1 zettabyte for the first time, and is expected to double every two years.[3] The amount of new digital content created in 2011 amounts to several million times that contained in all books ever written.[4] OECD figures show that Internet traffic has risen by $13,000 \%$ in the last decade, with more digital information created in 2008-2011 than in all of previous recorded history.[5] By the end of 2012, the global number of internet users reached 2.4 billion, $8 \%$ Y/Y growth and the emerging markets in the mobile Internet is the main driving force for growth. The global intelligent mobile phone users reached 1.1 billion, $\mathrm{Y} / \mathrm{Y}$ growth of $42 \%$, the global mobile internet 
traffic has been growing rapidly to internet total flow 13\%.[6] With increasing dependence on internet, people's reading and thinking habits have changed. If the library only provides the data catalogue to users, it may be engulf in the huge information flood.

The future library must promote its intelligence service, and convert from Information Service to Knowledge Services. By using Cloud Computing, Big Data, Artificial Intelligence and other technologies, the library can analyze users' interests and demands on the basis of their records and browsing history .The result is same that users query and get information, but before this, the library has made comprehensive analysis on initial query conditions and users' feature. The library helps users find "the knowledge that they do not know they do not know". Only with the finishing of the transformation, the library can realize the goal of users-oriented.

\subsection{Cultivation of Information Literacy}

The United States National Forum on Information Literacy defines information literacy as "... the ability to know when there is a need for information, to be able to identify, locate, evaluate, and effectively use that information for the issue or problem at hand."[7][8] Other definitions incorporate aspects of "skepticism, judgment, free thinking, questioning, and understanding..."[9] or incorporate competencies that an informed citizen of an information society ought to possess to participate intelligently and actively in that society citation needed.

Uneven development around the world has led to huge difference in people's information literacy. Access to information is a fundamental human right that can break the cycle of poverty and support sustainable development. Libraries serve all people, regardless of their race, national or ethnic origin, gender or sexual preference, age, disability, religion, economic circumstances or political beliefs. [1]

However, the development of technology didn't bring up the level of human's information literacy. Users may know how to use computer and internet, but many of them lack the basic research skill, and don't have complete information literacy and intellectual ability. Users can't effectively retrieve valuable information because they don't know what they exactly want.

In order to help uses to access information effectively and easily, the library should work in the following aspects:

Expanding reading resources in new technology platform. For example, developing information service platform on mobile internet, producing mobile reading equipment which is cheap and fine, and teaching people how to use it.
Using new technology to make up the difference on information literacy between people. For example, by using artificial intelligence technology the internet device has functions of voice recognition, Machine Translation and speech synthesis, so it can support real-time multilingual speech translation.

Protecting the environment of paper reading, providing the most original reading experiences and promoting the joy of reading for people.

\section{OPTIMIZATION OF RESOURCE CONFIGURATION MODE}

\subsection{Collection and Preservation of Born-digital Resources}

No matter what era of change, the library has always assumed the preservation and dissemination of human civilization functions. With categories of information expanding, if only to preserve the traditional literatures (both print and electronic version) cannot contain all of human civilization, because more and more information exist in the form of pictures, medias, and other paperless forms etc.

In September 2013, the National Security Agency's (NSA) new data center in Utah in the United States was open. NSA is capable of storing up to 12 exabytes $(12,000$ petabytes) of information. To put that in perspective, just 400 terabytes would be needed to store all the books ever written in any language, and with 1,000 terabytes in 1 petabyte, that's less than $1 \%$ of NSA's new Utah center's storage capacity $(0.0033 \%)$.

With the popularity of social networking tools, new mode of transmission of information can't be ignored. Libraries should digitize the original entity resources, at the same time pay more attention on the collection and preservation of born-digital resources. In April 2010, Library of Congress and Twitter signed an agreement providing the Library the public tweets from the company's inception through the date of the agreement, an archive of tweets from 2006 through April 2010. By January 2013, the Library have an archive of approximately 170 billion tweets and growing. The volume of tweets the Library receives each day has grown from 140 million beginning in February 2011 to nearly half a billion tweets each day as of October 2012. [10] Funding, rational planning and professional skills are three major problems of management and preservation of Born-digital Resources.

\subsection{Participate in online education}

The rapid expansion of global educational resources brings more opportunity to learn, and education becomes cheaper and more convenient. Along with the technical barriers to developing countries declined, popularization rate of mobile devices is 
also more and more high. These facts have accelerated educational globalization and mobile education. Mobile technology has promoted the emergence of Massive Open Online Courses (MOOC) and the opening of global classroom. Since February 2014, the British Library began to provide MOOC services, which sets the precedent for national libraries around the world.

Artificial intelligence will be widely used in global online education. Some day in the future, the automatic translation will completely break the language barrier, and change the mode of communication. In the area of local education resources limited, students can use the translation tool to study abroad. Anyone not only researchers can use the translation tools for reading and writing.

The library should not only provide information to the local community, but increase exchanges and fusion between different regions, different cultural. Therefore, the library should make efforts to break the geographical constraints of education and language barriers, to provide seamless learning resources for people all over the world. Lifelong learning will be accepted as a universal value. So informal learning experiences will get more and more recognition, and the understanding between cultures and races will further.

\section{INNOVATION OF ORGANIZATION AND MANAGEMENT}

\subsection{Becoming the Community Center of Users}

The increasing of digital resources in libraries makes network traffic growing, at the same time the number of users visiting entity resources continues to decline, which forces libraries to think about the role they should play in the network age. On the other hand, to exchange ideas face to face is expected by users. As the center of gathering and communicating information and intelligence, how to make full use of the entity space value becomes very important to libraries.

As center of knowledge and public service, the library can gather user groups who have common interest, and expand visibility to gather more user through network. Providing platform for sharing information, the library can be the place where professional cultural groups engage in a variety of activities. The entity library will be the communication center where professional cultural groups can share document, music, video and game resources, engage in a variety of activities. People who used to information life, can also go to the library to access to education, health, employment and other information of interest to them, or look for business support, access to training, job seeking professional help.

\subsection{Providing Expert Guidance}

Digital and Networks Service require the library to reorient themselves in information generating, spreading and processing. Librarians need to screening, evaluation and organization of network information resources. This is a very complex work. For example, how to help users to seek for information actively if they neither know what they exactly want nor how to retrieval accurately? The library need professionals to write briefs with highlight theme, and put them to news web-site, microblog, RSS, and even Social Network and tell people how to obtain those resources freely. Librarians must have the ability to provide customized information by selecting and filtering, and help people to read effetely.

Librarians who have ability of analysis and integration on huge information, can also play a role in other fields. Such as member of the research team, project application, agency review members, data analyst, and community partner.

\section{SUMMARY}

The popularization of Internet, knowledge of digital and social networking tools, profoundly influence the development direction of the library. The Library must persist in the idea of take the user as the center, constructing resource configuration mode for information environment, form a flexible form of organization and management, and become intelligence center which provides knowledge and public service.

\section{REFERENCES}

[1] IFLA Statement on Libraries and Development, the IFLA Governing Board in Singapore. August 162013.

[2] IFLA Trend Report, the IFLA Governing Board in Singapore. August 192013

[3] International Data Corporation (2011)'The 2011 Digital Universe Study: Extracting Value from Chaos' http://www.emc.tom/collateral/demos/microsites/emc-digitaluniverse-2011 /index.htm

[4] DEvolving (2011)'Truth, Lies and the Internet: a report into young people's digital fluency p 12 http://www.demos.co.uk/files/Truth_web.pdf

[5] World Economic Forum (2012)'Global Information Technology Report: living in a yapper-connected world' $p$ 59http://www3.weforum.org/dots/Global_IT_Report_ 2012.pdf

[6] Internet Rrends D11 Conference, Mary Meeker/Liang Wu, May 29, 2013.

[7] "What is the NFIL?" National Forum on Information Literacy. Retrieved October 25, 2012.

[8] Jump up $\wedge$ "Presidential Committee on Information Literacy: Final Report". January 10, 1989. Retrieved October 25, 2012.

[9] Jump up ^ Gillmor, Dan. "Mediactive". Retrieved February 2, 2013.

[10] Update on the Twitter Archive at the Library of Congress, Erin Allen. January 4, 2013. 